\title{
Influência da irrigação sobre a disponibilidade, a composição química, a digestibilidade e o consumo dos capins mombaça e napier ${ }^{1}$
}

\author{
Jorge Guilherme Bergottini Palieraqui ${ }^{2}$, Carlos Augusto de Alencar Fontes ${ }^{3}$, Enilson Geraldo \\ Ribeiro ${ }^{4}$, Antônio Carlos Cóser 5 , Carlos Eugênio Martins ${ }^{5}$, Alberto Magno Fernandes ${ }^{3}$ \\ 1 Parte da dissertação de Mestrado do primeiro autor apresentada ao Programa de Pós-Graduação em Produção Animal, CCTA/UENF. \\ 2 Mestre em Zootecnia. \\ 3 UENF/CCTA/LZNA, Av. Alberto Lamego, 2000 - Campos dos Goytacazes, RJ, CEP: 28013-602. Bolsista do CNPq. \\ ${ }^{4}$ Doutor em Zootecnia. \\ ${ }^{5}$ Embrapa Gado de Leite, Rua Eugênio do Nascimento, 610, Dom Bosco, Juiz de Fora, MG, CEP: 36038-330. Bolsista do CNPq. \\ * Bolsista do CNPq.
}

RESUMO - Avaliou-se o efeito da irrigação sobre a produção de biomassa e o valor nutritivo de Panicum maximum, Jacq., cv. Mombaça e Pennisetum purpureum, Schum cv. Napier. O experimento foi composto de quatro tratamentos, constituídos pelas combinações de dois níveis de irrigação e das duas forrageiras. O delineamento experimental foi o de blocos completos casualizados, com parcelas subdividas no tempo e no espaço, com mais de uma unidade experimental por subclasse. As forrageiras foram avaliadas sob pastejo rotacionado, utilizando-se novilhos F1 Europeu-Zebu (peso inicial de $260 \mathrm{~kg}$ ) e carga animal variável, mantendo-se pressão de pastejo de $4 \mathrm{~kg}$ de MS foliar/100 kg de PV. Foi constatada maior disponibilidade de matéria seca total (MST) e matéria seca verde (MSV) no capim-napier, sendo observado o mesmo comportamento para o efeito de irrigação. Não houve diferença quanto à disponibilidade de matéria seca foliar (MSF). A irrigação ocasionou aumento da disponibilidade de MSF. Houve diferença nos teores de MS entre as forrageiras, observando-se teor mais elevado para o capim-mombaça. O teor de MS nas amostras de lâminas foliares foi maior que nas de extrusa. As forrageiras não diferiram quanto aos teores de $\mathrm{PB}, \mathrm{MO}$, cinzas e FDN, que não foram afetados pela irrigação. O capimmombaça apresentou maior DIVMS. Houve efeito linear do período de ocupação sobre a DIVMS e os teores de PB e FDN da extrusa, observando-se decréscimo da DIVMS da PB e acréscimo da DIVMS da FDN do 1으 para o 4으 dia de ocupação dos piquetes. Os consumos de MS e MO foram maiores para o capim-mombaça. Não houve diferença quanto ao ganho de peso vivo diário dos novilhos entre as espécies forrageiras e os níveis de irrigação.

Palavras-chave: análise química, desempenho animal, forragens tropicais

\section{Influence of irrigation on the availability, chemical composition, digestibility and intake of mombaçagrass and napiergrass}

\begin{abstract}
The work aimed to evaluate the effect of the irrigation on the production of biomass and the nutritional value of Panicum maximum, Jacq. cv. Mombaça and Pennisetum purpureum Schum, cv. Napier. Four treatments were tested, consisting of the combination of irrigation levels and two forages. A split-plot arrangement in time and space in a complete randomized block design was used, with more than one observation per treatment, per block. The forages were evaluated under rotational stocking, using F1 European-zebu steers, with average body weight (BW) of $260 \mathrm{~kg}$. It was used a variable stocking technique and target herbage allowance was $4 \mathrm{~kg}$ leaf dry matter per $100 \mathrm{~kg}$ animal BW. Total and green DM availabilities were greater for napiergrass than for mombaçagrass, being observed the same pattern for the irrigation effect. The forages did not differ regarding the leaf DM (LDM) availability. Irrigation increased LDM availability. Mombaçagrass showed higher DM concentration. The forages did not differ regarding the concentration of CP, OM, ash, NDF and ADF in DM, which were also not affected by irrigation. Mombaça-grass showed higher in vitro DM digestibility (IVDMD). Regression analysis showed linear increase of NDF and ADF concentration and linear decrease of IVDMD and CP concentration in extrusa from day one to day four during the grazing period. Values of intake were greater for mombaçagrass. There was no difference regarding the BW gain of steers between forages or irrigation levels.
\end{abstract}

Key Words: animal performance, chemical analysis, tropical forages 


\section{Introdução}

O Brasil é um dos maiores produtores de carne bovina, possuindo o maior rebanho comercial do mundo e, nos últimos anos, vem se firmando como o maior exportador de carne.

A pecuária de corte nacional, a partir da década de 90 , com o rebanho em expansão, melhorou significativamente quanto aos índices de produtividade. Em busca de maior eficiência de produção, os produtores brasileiros passaram a dar mais atenção à nutrição do rebanho, promovendo melhor utilização das pastagens e das culturas forrageiras, realizando o melhoramento genético do rebanho e aprimorando o controle sanitário e o manejo, o que proporcionou abate de animais em idades mais precoces. Apesar destas mudanças, quando comparada à de outros países produtores tradicionais, como a Argentina, a Austrália e os Estados Unidos, a produção nacional deixa muito a desejar em produtividade (Assis, 1997). Entretanto, o rebanho brasileiro ainda tem potencial para crescimento físico, embora o grande potencial para aumento da produção constitua-se no aumento da produtividade, que pode ser induzido por ganhos tecnológicos.

Mesmo com o desenvolvimento da pecuária nacional, alguns estados não possuem produção suficiente para atender à própria demanda. No estado do Rio de Janeiro, por exemplo, a carne consumida é, quase que totalmente, produzida em outros estados, como conseqüência do tamanho relativamente pequeno do rebanho e do pouco desenvolvimento desse setor em comparação ao de outros estados.

As regiões norte e noroeste do Rio de Janeiro têm condições altamente favoráveis à pecuária de corte, com solos de boa fertilidade e clima propício ao uso da irrigação de culturas forrageiras. Possuem ainda rebanhos zebuínos numerosos em relação a outras regiões do estado. Entretanto, o quadro atual da atividade, de modo geral, não reflete as condições favoráveis, pois não houve melhora do setor, como verificado nos principais pólos produtores do País. Porém, alguns produtores, motivados pelos avanços verificados em outros estados, investiram em tecnologia, melhorando as pastagens, intensificando os programas sanitário e de manejo e introduzindo raças melhoradas em programas de cruzamento no intuito de agregar maior valor ao produto.

A produção de grãos nessas regiões é muito pequena, o que onera o uso de suplementos concentrados na dieta animal. A produção de pastagens durante a estação de seca corresponde a aproximadamente $20 \%$ da observada no período das chuvas, fator preponderante para o baixo desempenho animal.
No entanto, apesar da baixa produção forrageira durante a estação seca, as condições climáticas destas regiões não impõem grande limitação ao desenvolvimento das forrageiras desde que corrigido o déficit hídrico, tanto no período de seca quanto nos veranicos observados durante a estação chuvosa. Há, entretanto, carência quase completa de estudos sobre o assunto nestas regiões.

Este trabalho foi realizado com o objetivo de estudar a influência da irrigação sobre a disponibilidade de forragem, a composição química, o consumo, a digestibilidade e o ganho de peso dos animais em pastagem de Panicum maximum, cv. Mombaça e Pennisetum purpureum Jacq., Schumcv. Napier durante a estação seca.

\section{Material e Métodos}

O experimento foi realizado no Núcleo de Pesquisa de Zootecnia do Laboratório de Zootecnia e Nutrição Animal do Centro de Ciências e Tecnologias Agropecuárias da UENF, em Campos dos Goytacazes - RJ, localizado a $21^{\circ} 44^{\prime} 47^{\prime \prime}$ de latitude sul, $41^{\circ} 18^{\prime} 2$ " de longitude oeste e 12 $\mathrm{m}$ de altitude. O clima da região é classificado como AW tropical quente úmido, com verões quentes e chuvosos e invernos secos. A precipitação média anual é de $1.020 \mathrm{~mm}$, sendo comum a presença de veranicos nos meses de janeiro e fevereiro. A temperatura média anual no período de 1996 a 1999, segundo informações (não publicadas) da Estação Meteorológica da UENF/PESAGRO-Rio, Campos dos Goytacazes, foi de $23^{\circ} \mathrm{C}$, com médias das máximas de $28,9^{\circ} \mathrm{C}$ e média das mínimas de $18,9^{\circ} \mathrm{C}$. No mesmo período, a temperatura média das mínimas nos meses mais frios (junho e julho) manteve-se acima de $15^{\circ} \mathrm{C}$ e a média das máximas foi superior a $23^{\circ} \mathrm{C}$, com temperaturas médias mensais acima de $20^{\circ} \mathrm{C}$ nesses dois meses.

$\mathrm{O}$ experimento teve duração de cinco meses (junho a novembro de 2002, coincidindo com a estação seca do ano) e compreendeu quatro tratamentos, constituídos pelas combinações de dois níveis de irrigação e duas forrageiras (Panicum maximumcv. Mombaça e Pennisetum purpureum cv. Napier). Nos tratamentos que incluíam irrigação, foram adotados turnos de rega de sete dias utilizando-se aspersores de baixa pressão. O volume de água aplicado em cada mês foi o necessário para repor a evapotranspiração de referência (média histórica) observada noCampus Avançado da Universidade Federal Rural do Rio de Janeiro, em Campos dos Goytacazes, em um período de dez anos. Deduziu-se do volume de irrigação previsto em cada ciclo o volume de precipitação pluviométrica verificado no ciclo.

O delineamento experimental foi em blocos completos casualizados (três blocos com três hectares cada) com 
parcelas subdivididas no tempo e no espaço, com mais de uma unidade experimental por subclasse (Steel \& Torrie, 1980). Cada bloco foi dividido em duas parcelas de 1,5 ha, nas quais foram alocadas, ao acaso, as duas forrageiras, de modo que cada parcela, em cada bloco, foi subdividida em seis subparcelas de 0,25 ha, nas quais foram alocados, aleatoriamente, os níveis de irrigação (ausência e presença).

As forrageiras foram avaliadas sob pastejo rotacionado, com quatro dias de ocupação e 32 de descanso utilizando-se novilhos F1 Europeu-Zebu (peso inicial de $260 \mathrm{~kg}$ ), criados em regime de pastagem exclusiva, com carga animal variável (put and take) para manter a pressão de pastejo constante de $4 \mathrm{~kg}$ de MSF/100 kg de PV. Foram utilizados 1,78 UA/ha (correspondente a quatro animais fixos por tratamento, em uma área de 2,25 ha em cada tratamento, totalizando 16 animais fixos) e o número necessário de reguladores para manter constante a pressão de pastejo. A suplementação aos animais consistiu apenas de mistura mineral.

O período experimental foi precedido de um período pré-experimental de 16 dias, sendo os animais identificados com brincos e submetidos a controle de parasitos. No início do experimento, os animais foram pesados após jejum de 14 horas e, durante o experimento (a cada 28 dias), foram pesados após jejum.

Em cada ciclo de pastejo, foram avaliadas, diretamente nas pastagens, as disponibilidades de MST, MSV e MSF por hectare e por piquete no dia anterior à entrada dos animais, sendo analisada a composição bromatológica (MS, PB, MO, FDN e cinzas) e quantificada, em amostras de extrusa, fezes e pastagem a digestibilidade in vitro das forragens, conforme metodologia descrita por Silva \& Queiroz (2002).

Os dados obtidos neste estudo foram analisados empregando-se um modelo estatístico no qual foram aco modados os efeitos de bloco (três blocos), de forrageira (duas), nível de irrigação (dois), de ciclo de pastejo (quatro ciclos), das interações bloco $\times$ forrageira, bloco $\times$ nível de irrigação e forrageira $\times$ nível de irrigação e da interação tripla bloco $\times$ forrageira $\times$ nível de irrigação, inclusive o efeito da repetição dentro da interação bloco $\times$ forrageira $\times$ irrigação.

Os blocos foram definidos em função dos valores iniciais de saturação de base (\%), pH e dos níveis de fósforo (ppm) e alumínio (meq/100 $\left.\mathrm{cm}^{3}\right)$ do solo.

Foram considerados fixos os efeitos de bloco, forrageira e nível de irrigação e, como aleatórios, os efeitos de repetição (forrageira e nível de irrigação) dentro de bloco. Foram utilizados apenas os animais experimentais para determinação do ganho de peso por animal e do consumo de pastagem, os quais foram pesados no início, a cada 28 dias e ao final do experimento.
Além das variáveis supracitadas, foram avaliados o ganho de peso por animal, o consumo diário, a digestibilidade das forragens e seus constituintes e o valor nutritivo da forragem consumida (extrusa), com base na sua composição bromatológica e digestibilidade in vitro, contrastando-seos resultados com aqueles obtidos em amostras das forragens colhidas por corte do material, a $30 \mathrm{~cm}$ acima do solo. Foram ainda pesquisadas as mudanças na composição química e na digestibilidade das extrusas correspondentes aos dias 1 , 2, 3 e 4 de pastejo, em um mesmo piquete.

Para as análises do ganho de peso dos novilhos, utilizou-se o modelo estatístico em que foram ajustados os efeitos da forrageira (duas), do nível de irrigação (dois) e da interação forrageira $\times$ nível de irrigação.

Nas análises de consumo e digestibilidade das forragens, foi utilizado o modelo estatístico acomodando os efeitos da forrageira (duas), do nível de irrigação (dois), do período (dois) e da interação forrageira $\times$ nível de irrigação.

As pastagens foram implantadas em solo aluvial, em área de baixada sedimentar de textura argilosa. O solo foi corrigido com calcário dolomítico, em quantidades necessárias para aumentar a saturação de bases para $60 \%$. Para correção dos níveis de fósforo, foram aplicados $500 \mathrm{~kg} / \mathrm{ha}$ de superfosfato simples $\left(100 \mathrm{~kg} / \mathrm{ha}\right.$ de $\left.\mathrm{P}_{2} \mathrm{O}_{5}\right)$ antes do plantio. Os piquetes de ambas as forrageiras foram pastejados pela primeira vez no início do experimento, após 12 meses de sua formação.

Antes do período experimental, a pastagem foi roçada a $30 \mathrm{~cm}$ de altura. Foram feitas adubações de manutenção de nitrogênio e potássio, aplicando-se, em cobertura, $400 \mathrm{~kg} / \mathrm{ha} / \mathrm{ano}$ de $\mathrm{N}$ na forma de sulfato de amônia e $200 \mathrm{~kg} / \mathrm{ha} /$ ano de $\mathrm{K}_{2} \mathrm{O}$ (cloreto de potássio), parcelados após o fim de cada período de ocupação dos piquetes.

A disponibilidade de forragem foi determinada no dia anterior à entrada dos animais em cada piquete. Utilizou-se um quadro metálico de $1 \mathrm{~m}$ de lado, com um dos lados aberto. A amostragem foi feita de forma sistemática, em diagonal, retirando-se seis amostras por piquete (correspondendo a 24 amostras por hectare). O material contido no quadro foi cortado a $30 \mathrm{~cm}$ do nível do solo.

A biomassa que constituía os quadros foi separada nas frações forrageira específica (Mombaça ou Napier) e invasoras, que foram pesadas. Uma subamostra da forrageira foi coletada, separada em folhas (lâmina), colmo e material morto e preparada para posteriores análises laboratoriais. Para estimar, de forma mais rápida, a quantidade de MS disponível, e calcular o número de animais reguladores utilizados, subamostras das forrageiras foram secas em forno microondas, segundo metodologia descrita por Oliveira (1998). 
Amostras representativas da extrusa foram obtidas em quatro novilhos fistulados no esôfago, semelhantes aos animais experimentais, de acordo com a técnica descrita por Bishop \& Froseth (1970). As amostras de cada um dos quatro dias de permanência dos animais nos piquetes foram processadas separadamente para avaliação das mudanças na composição e na digestibilidade das dietas, em cada dia. Desta forma, cada animal fistulado foi utilizado em rodízio, pastejando cada dia em um piquete correspondente a um tratamento diferente, junto com os animais experimentais.

O consumo alimentar dos animais experimentais foi estimado duas vezes na época da seca utilizando-se o método de produção fecal/indigestibilidade. A produção fecal diária foi estimada utilizando-se o indicador óxido de cromo $\left(\mathrm{Cr}_{2} \mathrm{O}_{3}\right)$. Em cada determinação, os animais receberam diariamente $10 \mathrm{~g}$ de $\mathrm{Cr}_{2} \mathrm{O}_{3}$, divididos em duas porções de $5 \mathrm{~g}$, ministradas oralmente duas vezes ao dia, às 8 e $15 \mathrm{~h}$, em cartucho de papel, durante 14 dias (sete de estabilização e sete de coleta). Nas determinações de cromo, utilizou-se o método colorimétrico (UV visível a $440 \mathrm{~nm}$ ). A digestibilidade da forragem (extrusa) foi determinada pelo método in vitro (Tilley \& Terry, 1963).

Tabela 1 - Disponibilidade média de MS total (MST) e de matéria seca verde (MSV) por ciclo de pastejo, em função do nível de irrigação e da forrageira

Table 1 - Average availability of total DM (TDM) and green DM (GDM) by grazing cycle, as a function of the irrigation level and forage species

\begin{tabular}{|c|c|c|c|}
\hline \multirow{2}{*}{$\begin{array}{l}\text { Nível de irrigaç } \\
\text { Irrigation level }\end{array}$} & \multicolumn{2}{|c|}{$\begin{array}{c}\text { Forrageira } \\
\text { Forage specie }\end{array}$} & \multirow[t]{2}{*}{$\begin{array}{l}\text { Média } \\
\text { Average }\end{array}$} \\
\hline & $\begin{array}{l}\text { Capim-mombaça } \\
\text { Mombaçagrass }\end{array}$ & $\begin{array}{l}\text { Capim-napier } \\
\text { Napiergrass }\end{array}$ & \\
\hline \multicolumn{4}{|c|}{$\begin{array}{c}\text { Disponibilidade de MST }(\mathrm{kg} / \mathrm{ha}) \\
\text { Availability of TDM }(\mathrm{kg} / \mathrm{ha})\end{array}$} \\
\hline Com irrigação & 2.389 & 5.643 & $4.016^{\mathrm{A}}$ \\
\hline $\begin{array}{l}\text { Irrigated } \\
\text { Sem irrigação }\end{array}$ & 1.416 & 4.831 & $3.123^{\mathrm{B}}$ \\
\hline $\begin{array}{l}\text { Non-irrigated } \\
\text { Média } \\
\text { Average }\end{array}$ & $1.902^{\mathrm{a}}$ & $5.237^{\mathrm{b}}$ & \\
\hline
\end{tabular}

\begin{tabular}{lccc}
\hline \multicolumn{4}{c}{$\begin{array}{c}\text { Disponibilidade de MSV (kg/ha) } \\
\text { Availability of } \operatorname{GDM}(\mathrm{kg} / \mathrm{ha})\end{array}$} \\
\hline $\begin{array}{l}\text { Com irrigação } \\
\begin{array}{l}\text { Irrigated } \\
\text { Sem irrigação }\end{array}\end{array}$ & 2.389 & 5.232 & $3.810^{\mathrm{A}}$ \\
$\begin{array}{l}\text { Non-irrigated } \\
\text { Média } \\
\text { Average }\end{array}$ & 1.416 & 4.459 & $2.937^{\mathrm{B}}$ \\
\hline
\end{tabular}

Médias acompanhadas de letras maiúsculas diferentes nas colunas e minúsculas nas linhas diferem entre si $(P<0,01)$ pelo teste $F$.

Means followed by different letters, capital letters in the columns and small letters in the rows, differ $(P<0.01)$ by $F$ test.
Nas análises estatísticas dos dados de consumo, utilizou-se um modelo estatístico considerando os efeitos da forrageira (dois), do nível de irrigação (dois) e da interação forrageira $\times$ nível de irrigação. Para as análises estatísticas da composição química e da digestibilidade in vitro das amostras de extrusas e das amostras coletadas manualmente, empregou-se o modelo no qual foram acomodados os efeitos da forrageira (dois), do nível de irrigação (dois), do tipo de amostragem (dois) e da interação forrageira $x$ nível de irrigação.

\section{Resultados e Discussão}

Houve maior produção $(\mathrm{P}<0,05)$ de MST e MVS do capim-napier em relação ao capim-mombaça, tanto nos tratamentos com irrigação quanto naqueles sem irrigação. Portanto, não houve efeito $(\mathrm{P}>0,05)$ da interação forrageira $\times$ nível de irrigação sobre as disponibilidades de MST e MVS (Tabela 1).

Os valores observados para as produções de MST e MSV foram muito semelhantes, o que pode estar relacionado ao corte de uniformização e à altura de corte $(30 \mathrm{~cm}$ do solo), realizado antes do início do período experimental. Entretanto, a produção do capim-napier, tanto em MST quanto em MVS, independentemente do nível de irrigação, foi superior à do capim-mombaça, como resultado da alta produção de caule. Todavia, embora não se tenha verificado efeito de interação, observou-se maior resposta à irrigação sobre a disponibilidade de MST para o capim-mombaça $(68,6 \%)$, enquanto, para o capim-napier, esse aumento foi de apenas $16,81 \%$ (Tabela 1). No capim-mombaça, $100 \%$ do material colhido foi constituído de folhas e, no capimnapier, irrigado e não irrigado, os valores foram de 34 e $36 \%$ de folhas e 66 e $74 \%$ de caule, respectivamente, provavelmente em decorrência da altura de corte adotada para as forrageiras.

A irrigação aumentou $(\mathrm{P}<0,05)$ as disponibilidades de MSF, que corresponderam a $68,71 \%$ (2.389 vs $1.416 \mathrm{~kg}$ ) e $25,7 \%$ (2.067 vs $1.645 \mathrm{~kg}$ ) nos capins-mombaça e napier, respectivamente, que não diferiram $(\mathrm{P}>0,05)$ entre si.

Os diferentes aumentos na produção de MS em reposta à irrigação, citados em diversos trabalhos (Aguiar et al., 2002; Müller et al., 2002; Fonseca et al., 2001; Matsumoto et al. 2001; Cóser et al., 1998; Meirelles et al., 2001), podem estar associados às condições de temperatura e luminosidade, aos níveis de adubação, à localização geográfica de cada região, aos intervalos entre as determinações e à altura de corte na avaliação.

Houve efeito significativo de forrageiras $(\mathrm{P}<0,01)$ e de método de amostragem sobre o percentual de MS $(\mathrm{P}<0,01)$ 
e a digestibilidade in vitro $(\mathrm{P}<0,05)$, apesar do efeito das interações método de amostragem $\times$ teor de $\mathrm{MS}(\mathrm{P}<0,05) \mathrm{e}$ forrageira $\times$ digestibilidade $(\mathrm{P}<0,01)$. Também houve efeito da interação forrageira $\times$ nível de irrigação $(\mathrm{P}<0,05)$ sobre o teor de FDN (Tabela 2).

Observou-se maior teor de MS no capim-mombaça em relação ao napier $(\mathrm{P}<0,01)$ e nas amostras obtidas por corte manual em relação às obtidas pela extrusa $(\mathrm{P}<0,01)$. A diferença entre métodos de amostragem foi maior no capim-mombaça que no napier, o que explica o efeito de interação verificado para forrageira e método de amostragem. Os teores inferiores de MS nas amostras da extrusa podem ser explicados pela incorporação de saliva à amostra mesmo utilizando-se bolsas coletoras providas de tela.

O teor mais elevado de FDN no capim-mombaça irrigado, em relação ao não irrigado (Tabela 2), pode estar associado ao aumento da altura da planta e à maior taxa de crescimento promovidos pela irrigação (Aguiar, 2000; Andrade et al.; 2002), o que, necessariamente, aumenta a formação de tecidos de sustentação na planta (Van Soest, 1994).

A digestibilidade in vitro do capim-mombaça foi maior que a do capim-napier $(\mathrm{P}<0,05)$, apesar do efeito da interação forrageira $\times$ método de amostragem. Este efeito provavelmente resultou da menor proporção de caule em relação a folhas do capim-mombaça. Porém, os valores de DIVMS destas forrageiras, neste trabalho, foram inferiores aos descritos na literatura (Lima et al., 2001; Clipes, 2003). Essas diferenças podem estar correlacionadas aos elevados níveis de FDN observados (Tabela 2).

Não houve efeito das interações forrageira $\times$ nível de irrigação, forrageira $\times$ método de amostragem e nível de irrigação $\times$ método de amostragem sobre os teores de MO, PB, sílica e cinzas na MS. Na Tabela 3 constam os teores médios de PB, cinzas, MO e sílica na MS das duas forrageiras, os dois níveis de irrigação e os dois métodos de amostragem.
Os teores de PB foram semelhantes nos tratamentos com e sem irrigação. Esse resultado contraria os relatos de alguns autores de que a irrigação tende a ocasionar diluição do nitrogênio nas forrageiras, em decorrência da maior produção de MS e/ou da aceleração da maturidade das plantas cultivadas (Botrel et al., 1991; Andrade et al., 2002). É possível que, neste estudo, a associação de elevado nível de adubação nitrogenada, irrigação e temperatura ambiente, não limitante ao crescimento, tenha proporcionado a manutenção de níveis elevados de PB nas forrageiras irrigadas. Os teores de cinzas, no entanto, foram próximos

Tabela 2 - Valores médios de MS, DIVMS e FDN na MS das forrageiras, métodos de amostragem e nível de irrigação, médias referentes às forrageiras, aos métodos de amostragem e aos níveis de irrigação e erropadrão

Table 2 - $\quad$ Average and standard errors of DM, IVDMD and NDF in the dry matter for forages species, sampling procedures and irrigation levels

\begin{tabular}{lcc}
\hline \multirow{2}{*}{$\begin{array}{l}\text { Fator } \\
\text { Factor }\end{array}$} & \multicolumn{2}{c}{$\begin{array}{c}\text { Forrageira } \\
\text { Forage specie }\end{array}$} \\
\cline { 2 - 3 } & $\begin{array}{c}\text { Capim-mombaça } \\
\text { Mombaçagrass }\end{array}$ & $\begin{array}{c}\text { Capim-napier } \\
\text { Napiergrass }\end{array}$ \\
\hline & MS (DIVMS) & MS (DIVMS) \\
& $D M(I V D M D)$ & $D M(I V D M D)$ \\
\hline Extrusa & $14,92 \pm 0,6^{\mathrm{Aa}}$ & $12,80 \pm 0,6^{\mathrm{Ab}}$ \\
Extrusa & $\left(52,50 \pm 0,76^{\mathrm{Aa}}\right)$ & $\left(54,06 \pm 0,76^{\mathrm{Ab}}\right)$ \\
Manual & $21,51 \pm 0,6^{\mathrm{Ba}}$ & $16,04 \pm 0,6^{\mathrm{Bb}}$ \\
Hand pluck & $\left(55,38 \pm 0,76^{\mathrm{Ba}}\right)$ & $\left(50,26 \pm 0,76^{\mathrm{Ab}}\right)$ \\
\hline & $\mathrm{FDN}$ & $\mathrm{FDN}$ \\
& $N D F$ & $72,58 \pm 1,46^{\mathrm{Aa}}$ \\
\hline Com irrigação & $77,01 \pm 1,46^{\mathrm{Aa}}$ & $74,31 \pm 1,46^{\mathrm{Aa}}$ \\
Irrigated & & \\
Sem irrigação & $72,06 \pm 1,46^{\mathrm{Aa}}$ & \\
Non-irrigated & & \\
\hline
\end{tabular}

Médias acompanhadas de letras minúsculas diferentes nas linhas e de letras maiúsculas nas colunas diferem entre si $(P<0,05)$ pelo teste Tukey. Means followed by different letters, small letters in the columns and capital letters in the rows, differ $(P<0.05)$ by Tukey test

Tabela 3 - Teores médios de PB, cinzas, MO e sílica na MS, em função da forrageira, do nível de irrigação e do método de amostragem Table 3 - Average values of CP, ash, OM and silica, on DM basis, as a function of forage species, irrigation level and sampling technique

\begin{tabular}{|c|c|c|c|c|c|c|}
\hline \multirow[t]{3}{*}{$\begin{array}{l}\text { Composição } \\
\text { Composition }\end{array}$} & \multicolumn{6}{|c|}{$\begin{array}{l}\text { Variável } \\
\text { Variable }\end{array}$} \\
\hline & \multicolumn{2}{|c|}{$\begin{array}{c}\text { Forrageira } \\
\text { Forage specie }\end{array}$} & \multicolumn{2}{|c|}{$\begin{array}{l}\text { Nível de irrigação } \\
\text { Irrigation level }\end{array}$} & \multicolumn{2}{|c|}{$\begin{array}{l}\text { Método de amostragem } \\
\text { Sampling technique }\end{array}$} \\
\hline & $\begin{array}{c}\text { Capim-mombaça } \\
\text { Mombaçagrass }\end{array}$ & $\begin{array}{l}\text { Capim-napier } \\
\text { Napiergrass }\end{array}$ & $\begin{array}{c}\text { Com irrigação } \\
\text { Irrigated }\end{array}$ & $\begin{array}{l}\text { Sem irrigação } \\
\text { Non-irrigated }\end{array}$ & $\begin{array}{l}\text { Extrusa } \\
\text { Extrusa }\end{array}$ & $\begin{array}{c}\text { Corte manual } \\
\text { Hand pluck }\end{array}$ \\
\hline $\mathrm{MO}(O M)$ & $87,08 \mathrm{a}$ & $86,96 a$ & $86,78 \mathrm{a}$ & $87,26 \mathrm{a}$ & $87,30 \mathrm{a}$ & $86,75 a$ \\
\hline Sílica (Silica) & $5,13 \mathrm{a}$ & $5,09 a$ & $5,14 a$ & $5,08 \mathrm{a}$ & $6,12 a$ & $4,10 \mathrm{~b}$ \\
\hline
\end{tabular}

Médias acompanhadas de letras minúsculas diferentes nas linhas, para a mesma variável, diferem $(P<0,01)$ pelo teste $F$.

Means followed by different letters in a row and same response variable, differ $(P<0.01)$ by Tukey test. 
aos observados por Mello et al. (2002) em cinco cultivares de Panicum maximum.

Não houve diferença $(\mathrm{P}>0,05)$ entre os teores de cinzas das amostras obtidas por corte manual e os das amostras da extrusa, embora, na extrusa, tenham sido observados valores numericamente mais elevados, talvezem virtude da incorporação de minerais pela saliva (Hoehne et al.,1967). Quanto aos teores de MO, houve pequenas oscilações, não significativas, semelhantes às ocorridas nos teores de cinzas.

Por meio da análise de regressão, observou-se efeito linear decrescente na DIVMS em função do dia de ocupação nos piquetes $(\mathrm{P}<0,01)$. O mesmo ocorreu para os teores de PB e FDN nas forrageiras avaliadas. Entretanto, este efeito não foi detectado para os teores de MS, MO e cinzas.

Conforme demonstrado na Tabela 4, não houve efeito $(\mathrm{P}>0,05)$ da interação espécie forrageira $\times$ nível de irrigação sobre os consumos de MS e MO por $100 \mathrm{~kg}$ de PV.

A irrigação não influenciou $(\mathrm{P}>0,05)$ os consumos de MS e MO por $100 \mathrm{~kg}$ de PV, entretanto, verificou-se diferença $(\mathrm{P}<0,05)$ entre espécies forrageiras para ambos os componentes, observando-se maiores valores para o capimmombaça. Embora não tenha ocorrido diferença no consumo de MS, os valores observados (Tabela 4) justifi-

Tabela 4 - Consumos médios de MS e MO (por $100 \mathrm{~kg}$ de PV e em quilos por dia) de acordo com as forrageiras e os níveis de irrigação

Table 4 - Average intake of DM and OM (per $100 \mathrm{~kg}$ of live weight per day) as affected by forage species and irrigation level

\begin{tabular}{|c|c|c|c|}
\hline \multirow{2}{*}{$\begin{array}{l}\text { Nível de irrigaçã } \\
\text { Irrigation level }\end{array}$} & \multicolumn{2}{|c|}{$\begin{array}{c}\text { Forrageira } \\
\text { Forage specie }\end{array}$} & \multirow[t]{2}{*}{$\begin{array}{l}\text { Média } \\
\text { Average }\end{array}$} \\
\hline & $\begin{array}{c}\text { Capim-mombaça } \\
\text { Mombaçagrass }\end{array}$ & $\begin{array}{l}\text { Capim-napier } \\
\text { Napiergrass }\end{array}$ & \\
\hline \multicolumn{4}{|c|}{$\begin{array}{l}\text { Consumo de MS/100 kg de PV } \\
\text { Intake of } D M / 100 \mathrm{~kg} \text { of } B W\end{array}$} \\
\hline $\begin{array}{l}\text { Com irrigação } \\
\text { Irrigated }\end{array}$ & 3,25 & 2,87 & $3,06 \mathrm{~A}$ \\
\hline $\begin{array}{l}\text { Sem irrigação } \\
\text { Non-irrigated }\end{array}$ & 2,98 & 2,90 & $2,94 \mathrm{~A}$ \\
\hline $\begin{array}{l}\text { Média } \\
\text { Average }\end{array}$ & $3,11^{\mathrm{a}}$ & $2,88 \mathrm{~b}$ & \\
\hline
\end{tabular}

\begin{tabular}{lccc}
\hline & $\begin{array}{c}\text { Consumo de MO/100 kg de PV } \\
\text { Intake of } O M / 100 \mathrm{~kg} \text { of } B W\end{array}$ & \\
\hline $\begin{array}{l}\text { Com irrigação } \\
\text { Irrigated }\end{array}$ & 2,51 & 2,08 & $2,29 \mathrm{~A}$ \\
$\begin{array}{l}\text { Sem irrigação } \\
\text { Non-irrigated } \\
\text { Média } \\
\text { Average }\end{array}$ & 2,31 & 2,21 & $2,26 \mathrm{~A}$ \\
\hline
\end{tabular}

Médias acompanhadas de letras minúsculas diferentes nas linhas e de letras maiúsculas nas colunas diferem $(P<0,01)$ pelo teste $F$.

Means followed by different letters, small letters within a column and capital letters in a row differ $(P<0.01)$ by $F$ test. cam-se pela oferta de volumoso de boa qualidade, oriundo de um solo adubado corretamente com nitrogênio, fósforo e potássio, em um sistema de pastejo rotativo no qual foram utilizados novilhos em crescimento. Além disso, a digestibilidade destas forrageiras (Tabela 2) foi considerada boa para uma gramínea tropical.

Os valores de consumo verificados tanto no capimmombaça quanto no napier não diferiram dos obtidos em outros trabalhos (Cândido et al., 2002; Euclides et al., 1999) envolvendo as espécies Panicum maximum sp. e Penisentum purpureum sp, mesmo que haja grandes variações nas avaliações de consumo de MS destas forrageiras, com pontos extremos de 1,65 a 2,86\% do PV para animais em crescimento (Deresz \& Mozer, 1990).

Não houve diferença $(\mathrm{P}>0,05)$ quanto ao ganho de peso médio diário dos animais testers entre forrageiras e níveis de irrigação.

O ganho de peso médio diário dos animaistesters para os quatro tratamentos foi, respectivamente, 0,920;0,840; 0,820 e $0,930 \mathrm{~kg}$, respectivamente, para os capins mombaça irrigado e não irrigado e napier irrigado e não irrigado.

A ausência de diferença entre tratamentos justifica-se pelo fato de que os animais dos quatro tratamentos tiveram, durante todo o período experimental, disponibilidade igual de alimento, mantendo-se a oferta constante, de $4 \mathrm{~kg}$ de $\mathrm{MSF} / 100 \mathrm{~kg}$ de PV, nos quatro tratamentos.

\section{Conclusões}

As produções de MS total e de MS verde do capimnapier são superiores às do capim-mombaça, sem diferença detectável para a produção de MS foliar.

A irrigação aumenta a disponibilidade de ambas as forrageiras, com maior resposta para o capim-mombaça, principalmente quando relacionada à produção de MS foliar. Além disso, o consumo de MS para esta forrageira em condições de pastejo rotacionado é maior que para o capim-elefante na região em que este estudo foi realizado.

\section{Literatura Citada}

AGUIAR, A.P.A. Uso de forrageiras do grupo Panicum em pastejo rotacionado para vacas leiteiras. In: SIMPÓSIO DE FORRAGICULTURA E PASTAGENS: TEMAS EM EVIDÊNCIAS, 2000, Lavras. Anais... Lavras: Universidade Federal de Lavras, 2000. p.69-146.

AGUIAR, P.A.; DRUMOND, L.C.D.; SILVA, A.M. et al. Avaliação de características de crescimento e produção do capim Panicum maximum Jacq. cv. Mombaça sob condições irrigadas e em sequeiro em ambiente de cerrado. In: REUNIÃO ANUAL DA SOCIEDADE BRASILEIRA DE ZOOTECNIA, 39., 2002, Recife. Anais... Recife: Sociedade Brasileira de Zootecnia, 2002. (CD-ROM). 
ANDRADE, A.C.; FONSECA, D.M.; LOPES R. et al. Disponibilidade de matéria seca e composição química do capim-elefante Napier sob adubação e irrigação. In: REUNIÃO ANUAL DA SOCIEDADE BRASILEIRA DE ZOOTECNIA, 39., 2002, Recife. Anais... Recife: Sociedade Brasileira de Zootecnia, 2002. (CD-ROM).

ASSIS, A.G. Produção de leite no Brasil. In: SIMPÓSIO INTERNACIONAL SOBRE PRODUÇÃO ANIMAL EM PASTEJO, 1997, Viçosa, MG. Anais... Viçosa, MG: Universidade Federal de Viçosa, 1997. p.471.

BISHOP, J.P.; FROSETH, J.A. Improved techniques in esophageal fistulization of sheep. American Journal Veterinary Research, v.31, n.8, p.1505-1507, 1970.

BOTREL, M.A.; ALVIM, M.J.; XAVIER, D.F. Efeito da irrigação sobre algumas características agronômicas de cultivares do capim-elefante. Pesquisa Agropecuária Brasileira, v.26, n.10, p.1731-1736, 1991.

CÂNDIDO, M.J.D.; ALEXANDRINO, E.; GOMIDE, J.A. Comparação do consumo e desaparecimento de matéria seca de forragem em pasto de capim-Mombaça (Panicum maximum Jacq.) sob pastejo rotativo. In: REUNIÃO DA SOCIEDADE BRASILEIRA DE ZOOTECNIA, 39., 2002, Recife. Anais... Recife: Sociedade Brasileira de Zootecnia, 2002. (CD-ROM).

CLIPES, R.C. Métodos de amostragem qualitativa e composição químico-bromatológica de forrageiras tropicais sob pastejo rotacionado. Campos dos Goytacazes: Universidade Estadual Norte Fluminense, 2003. 69p. Dissertação (Mestrado em Produção Animal) - Universidade Estadual Norte Fluminense, 2003.

CÓSER, A.C.; MARTINS, C.E.; CARDOSO, F.P.N. Produção de leite em pastagem de capim-elefante submetida a duas alturas de resíduo pós-pastejo. In: REUNIÃO ANUAL DA SOCIEDADE BRASILEIRA DE ZOOTECNIA, 36., 1998, Botucatu. Anais... Botucatu: Sociedade Brasileira de Zootecnia, 1998. (CD-ROM).

DERESZ, F.; MOZZER, O.L. Produção de leite em pastagem de capim-elefante. In: SIMPÓSIO SOBRE CAPIM-ELEFANTE, 1990, Juiz de Fora. Anais... Juiz de Fora: Embrapa Gado de Leite, 1990. p.155-172.

EUCLIDES, V.P.B.; THIAGO L.R.L.S.; MACEDO, M.C.M. et al. Consumo voluntário da forragem de três cultivares dePanicum maximum sob pastejo. Revista da Sociedade Brasileira de Zootecnia, v.28, n.6, p.1177-1185, 1999.

FONSECA, D.M.; ANDRADE, A.C.; QUEIROZ, D.S. et al. Adubação nitrogenada e potássica em capim-elefante cv. Napier sob pastejo rotativo. In: REUNIÃO ANUAL DA SOCIEDADE BRASILEIRA DE ZOOTECNIA, 39., 2001, Piracicaba. Anais... Piracicaba: Sociedade Brasileira de Zootecnia, 2001. (CD-ROM).

HOEHNE, O.E.; CLANTON, O.C.; STREETEK, C.L. Chemical changes in esophageal fistulas samples caused by salivary contamination and samples preparation. Journal of Animal Science, v.26, n.3, p.628-631, 1967.
LIMA, M.L.P.; BERCHIELLI, T.T.; NOGUEIRA, J.R. et al. Estimativa do consumo voluntário do capim-tanzânia (Panicum maximum, Jacq. cv. Tanzânia) por vacas em lactação sob pastejo rotacionado. Revista Brasileira de Zootecnia, v.30, n.6, p.1919-1924, 2001.

MATSUMOTO, E.; ISEPON, O.J.; BASTOS, J.F.P. et al. Produção de matéria seca de cinco cultivares de Panicum maximum Jacq. submetidos à irrigação. In: REUNIÃO ANUAL DA SOCIEDADE BRASILEIRA DE ZOOTECNIA, 39., 2001, Piracicaba. Anais...Piracicaba: Sociedade Brasileira de Zootecnia, 2001. (CD-ROM).

MEIRELleS, P.R.L.; MOCHIUTTI, S.; PEREIRA, A.V. Competição do genótipo de capim-elefante (Pennisetum purpureum Schum.) em área de vársea alta no Amapá. In: REUNIÃO ANUAL DA SOCIEDADE BRASILEIRA DE ZOOTECNIA, 39., 2001, Piracicaba. Anais... Piracicaba: Sociedade Brasileira de Zootecnia, 2001. (CD-ROM).

MELLO, S.Q.S.; ALVES, J.B.; BERGAMASCHINE, A.F.et al. Produção de matéria seca e composição bromatológica de cultivares de Panicum maximum Jacq. em diferentes idades de corte. In: REUNIÃO ANUAL DA SOCIEDADE BRASILEIRA DE ZOOTECNIA, 3.9, 2002, Recife.Anais... Recife: Sociedade Brasileira de Zootecnia, 2002. (CD-ROM).

MÜLLER, M.S.; FANCELLI, A.L.; NETO, D.D. et al. Produtividade do Panicum maximun cv. Mombaça irrigado, sob pastejo rotacionado. Scientia Agrícola, v.9, n.3, p.427-433, 2002.

OLIVEIRA, J.S.E. Produção e utilização de silagem de milho e sorgo. Juiz de Fora: Embrapa Gado de Leite, 1998. p.34. (Circular Técnica, 47).

SILVA, D.J.; QUEIROZ, A.C. Análise de alimentos: métodos químicos e biológicos. 3.ed. Viçosa, MG: Universidade Federal de Viçosa, 2002. 235p.

STEEL, R.R.D.; TORRIE, J.H. Principles and procedures of statistics. A biometrical approach. 2.ed. New York: Mc GrawHill, Book Company, 1980. 633p.

TILLEY, J.A.; TERRY, A.R. A two-stage technique for in vitro digestion of forage crops. Journal British Grassland Society, v.18, n.1, p.104-111, 1963.

Van SOEST, P.J. Nutritional ecology of the ruminant. 2.ed. Ithaca: Cornell University Press, 1994. 476p. 